\title{
Processing Aids for Improving Heat Transfer during Drying of Granular Food Materials
}

\section{Chenchaiah Marella ${ }^{1 *}$ and K. Muthukumarappan²}

${ }^{1}$ Research Associate IV/Manager, Institute for Dairy Ingredient Processing, Dairy Science Department, South Dakota State University, Brookings, SD 57006, USA ${ }^{2}$ Distinguished Professor and Graduate Program coordinator, Agricultural and Biosystems Engineering Department, South Dakota State University, Brookings, SD 57007, USA

\begin{abstract}
The comparative low price of energy in the past discouraged any emphasis on energy conservation in drying of food products. But under the circumstances of ever increasing energy prices, it is the need of the hour to look for improved energy utilization. In dairy and food industry a large number of products are dried. Previously this operation was carried out in a single stage, necessitating the dryer to operate at higher air out let temperatures. To improve this, dryers were developed with two and three stages. Additional stages brought about significant savings in the energy requirements. Fluidized beds have been included as second and third stage dryer in conventional dryers. Inclusion of vibrations, centrifugal beds, immersion heaters etc have been tried to improve the heat transfer characteristics of the air - material drying situations. In the present work, various processing aids that improve the heat transfer in drying of granular material are reviewed. In addition, data from drying of acid casein, wheat and shelled corn were also resented.
\end{abstract}

Keywords: Processing aids; Heat transfer; Granular material; Fluidized beds; Vibrofluidization; Drying rate

\section{Introduction}

Generally drying is the removal of moisture from a food product by thermal means [1]. Drying processes are important steps in chemical and food processing plants and in storage and processing of food grains [2]. Although most of the drying research and development has taken place during the past 4-5 decades, the technique of drying is an age old operation. The stabilization of perishable products by drying was used by primitive people for millions of years [3]. The first record of articificial drying of foods appeared in $18^{\text {th }}$ century [4].

The basic objective in drying of food products is to preserve them. By reducing the moisture content of the product, the dehydration process makes it possible to limit microbial growth and other reactions. It also preserves its flavor and nutritional characteristics [1]. Packing, handling, transportation and storage of dry product are easier and cheaper, because the weight and volume of the product are less and it is in dried form [5].

In dairy and food industry, a large number of products are spray dried. Previously this operation was being carried out in a single stage. This requires the dryer to run at a relatively high temperature and lower moisture content of the outlet air. This results in high energy consumption. The comparative low prices of energy in the past discouraged any emphasis on energy conservation. But with the ever increasing prices of energy, it is important to focus on improved energy management and utilization. This is the need of the hour inorder to avoid depletion of the natural resources as well as escalation of processing costs. The focus of the efforts should be in the direction of development of actual drying processes to make them consume less energy, to improve the existing dehydration systems and to develop heat recovery systems.

Lately, increasing attention has been paid to improve the already existing systems of drying. For example in the spray drying of dairy and food products, introduction of fluidized beds and Vibrofluidized beds resulted into considerable energy savings. Spray dryers have been developed as two stage and three stage dryers that resulted into energy savings to the extent of 20 and $30 \%$ respectively. The latest version of these developments in the concept of Integrated Fluidized Bed Dryer (IFD). Through this concept, nearly $50 \%$ savings in energy became possible [6]. In the preceding sections, we presented information on processing aids that improve the drying and dehydration of dairy and food products.

\section{Fluidizations}

The technique of fluidization is not a new concept [7]. During the past several years, a series of modifications have been incorporated in to fluidized bed systems so as to make them suitable for processing of a large variety of food products. Some of these are vibrated fluidized bed systems for particles of wide size distribution and sticky nature. Two and multi stage fluidized bed systems for high moisture containing foods, centrifugal fluidized bed systems for sticky, piece form and high moisture foods etc. With these developments, virtually no food product is unsuitable for processing in fluidized bed systems.

Conventional fluidization: Fluidization is one of the commonly used technologies in drying of dairy, food and agricultural material [8]. It is a gentle, uniform method, capable of drying the material down to very low moisture content. Fluidized bed drying systems contains granular or powder form of food product on a perforated screen. Drying medium or hot air is allowed to pass through the bed of food material. When the velocity of the gas flowing up through a mass of solid particles is insufficient to lift or support any of the solid, the mass

*Corresponding author: Chenchaiah Marella, Research Associate IV/Manager Institute for Dairy Ingredient Processing, Dairy Science Department, South Dakota State University, Brookings, SD 57007, USA, Tel: 605688 4184; Fax: 605688 6276; E-mail: Chenchaiah.marella@sdstate.edu

Received July 31, 2013; Accepted August 24, 2013; Published August 30, 2013

Citation: Marella C, Muthukumarappan K (2013) Processing Aids for Improving Heat Transfer during Drying of Granular Food Materials. J Food Process Technol 4: 258. doi:10.4172/2157-7110.1000258

Copyright: $\odot 2013$ Marella C, et al. This is an open-access article distributed under the terms of the Creative Commons Attribution License, which permits unrestricted use, distribution, and reproduction in any medium, provided the original author and source are credited. 
is called a fixed bed (Figure 1a). With increasing fluid velocities, in the absence of channeling, the pressure drop through the bed rises until it approaches the net effective weight of the solid per unit area, when the packing arrangement of the particles becomes more open so that the bed expands: with further increase in velocity the particles are fully supported and the expanding bed becomes fluidized (Figure 1b). For any fluidization, the velocity at which fluidization starts and the velocity at which slugging and enhanced rate of entrainment occurs are the two limits of the operating range. The velocity at which fluidization starts is known as minimum fluidization velocity. Further increase in air velocity causes bubbling in the bed of the material (Figure 1c). When the air velocity is far greater than the terminal fall velocity of the particles, the particulate material are carried along with the upward flowing air (Figure 1d).

A non-vibrated fluidized bed system is generally termed as conventional fluidized bed system. It is mainly useful for processing of products of homogeneous physical and chemical characteristics. When compared to other dehydration systems, the fluidized bed systems offer several advantages such as 1). Even flow of fluidized particles permitting continuous, automatically controlled, large scale operation with easy handling of feed and the product, 2). By rapid exchange of heat and mass transfer, overheating and case hardening of the product is avoided, 3). Rapid mixing of solids leads to nearly isothermal conditions throughout the bed, 4) It is possible to get instantized product in single stage.

Marella et al. [9-11] conducted a series of experiments in a Vibrofluidized bed system using acid casein, corn, wheat and skim milk powder. In this study, the impact of fludization on the drying rate of casein curd was studied. Using the Vibrofluidized bed system designed and developed by Marella et al. [12], and the mathematical model developed for the Vibrofluidized bed [12], $0.7 \mathrm{~kg}$ of wet acid casein was dried under stagnant and fluidized conditions. From the data presented in (Figure 2), it is seen that the fluidization of the bed of casein curd resulted into an $8 \%$ increase in the initial drying rate obtained for the drying process. This increase in Ri at the incipient of fluidization was shown to be due to improved bed agitation, thereby increasing the area exposed to hot air.

Vibrofluidizations: Incorporation of vibrations into fluidized bed systems reduces the resistance to heat and mass transfer processes. Good mixing of the material in the vibrated beds causes enhanced removal of moisture. Vibroluidized bed and vibrating conveyor dryer etc systems uses the vibrational mechanism inorder to improve the drying rates and heat transfer characteristics. When the bed is vibrated at its resonant frequency, it will be requiring less energy. In other words, with the given small energy input at the resonant frequency large amplitude can be developed to suit vibrofluidization. Further, by adjusting mass and spring characteristics of the Vibrofluidized beds, it is possible to shift the resonant frequency to produce and easily control desired acceleration. It is very essential to vibrate the bed at tis resonant frequency. At resonant frequency, optimum values of vibratory acceleration is obtained with the minimum energy input. For example, Sinz and Lund [13] reported $5 \mathrm{~g}$, Mushtaev et al. [14] reported $2-3 \mathrm{~g}$ and Marella et al. [9] reported $1.7 \mathrm{~g}$ as the optimum vibratory acceleration for drying of food stuff in vibratory fluidized beds. At resonance, highly agitated bed will be obtained with minimum effort. This is perhaps the reson for different researchers reporting widely varying acceleration optima. Several researchers [15-18] reported increase in drying rate due to vibrations. Marella et al., [9] used vibrofluidizations in order to increase the heat transfer coefficients in drying of dairy and agricultural foods grains. Heat transfer coefficients obtained for drying of some dairy and agricultural produce are given in (Table 1) [19]

Incorporation of vibrations showed a $25 \%$ reduction in air velocity needed to incipiently fluidize the acid casein bed (Figure 3 ). This directly amounts to energy savings equivalent to $25 \%$. Also, incorporation of vibrations resulted into a $10 \%$ higher initial drying rate (Figure 2) when compared to a non vibrated but fluidized bed and a $19 \%$ increase in initial drying rate when compared to a stagnant bed. Ramesh and Srinivasa Rao [20] reported easy fluidization and smooth transportation of material while drying cooked rice in vibrofluidized bed dryer.

Even though several advantages have been reported for vibrofluidizations in drying of granular food stuffs, very few

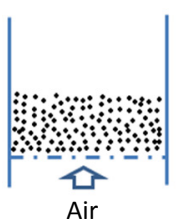

(a)

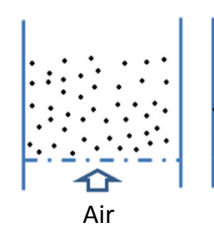

(b)

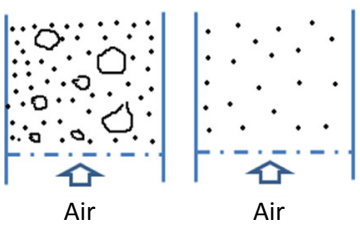

(c) (d) a. Gas velocity is < fluidization velocity - Fixed bed

b. Gas velocity = fluidization velocity - Incipiently fluidized bed

c. Gas velocity > fluidization velocity - bubbling in the bed

d. Gas velocity is far greater than the terminal fall velocity of the particles - pneumatic transportation

Figure 1: The process of fluidization.

\begin{tabular}{|c|c|c|}
\hline Product & Particle size & Heat transfer coefficient \\
\hline & $\mathrm{mm}$ & $\mathrm{W} / \mathrm{m}^{2} \mathrm{~K}$ \\
\hline Acid Casein & \\
\hline Wheat $^{*}$ & 3 & $300-350$ \\
\hline Coarse Particles & 4 & $75-150$ \\
\hline EdamChhese & $\mathrm{NA}$ & $100-300$ \\
\hline SMP $^{*}$ & $\mathrm{NA}$ & 350 \\
\hline \multicolumn{2}{|c|}{${ }^{*}$ Bed weight $-0.7 \mathrm{~kg}$, Bed area $-0.0552 \mathrm{~m}^{2}}$. \\
\hline Vibratory acceleration $-1.7 \mathrm{~g}$, Air velocity $-0.7 \mathrm{~m} / \mathrm{s}$ and air temperature $-63.7^{\circ} \mathrm{C}$ \\
\hline
\end{tabular}

Table 1: Heat transfer coefficients obtained during drying of dairy and food materials in a Vibrofluidized bed $[9,10,19]$.

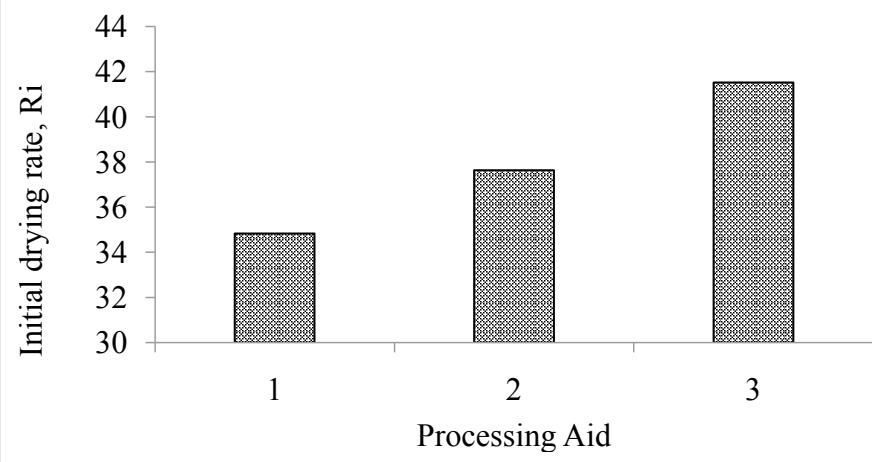

Figure 2: Effect of processing aids on initial drying rate: 1) is stationary bed $(0.7 \mathrm{~m} / \mathrm{s}$ air velocity) 2$)$ is fluidized bed $(0.93 \mathrm{~m} / \mathrm{s}$ air velocity) and 3$)$ is vibrofluidized bed $(0.7 \mathrm{~m} / \mathrm{s}$ air velocity). Product- Acid casein, Particle size $3.075 \mathrm{~mm}$, Bed weight $-0.7 \mathrm{~kg}$, Bed area $-0.0552 \mathrm{~m}^{2}$, Air temperature -63.7 $\mathrm{C}, \mathrm{Ri}-\mathrm{kg}$ water evaporated/ $\mathrm{kg}$ bone dry material per $\mathrm{m}^{2}$ per hour. 


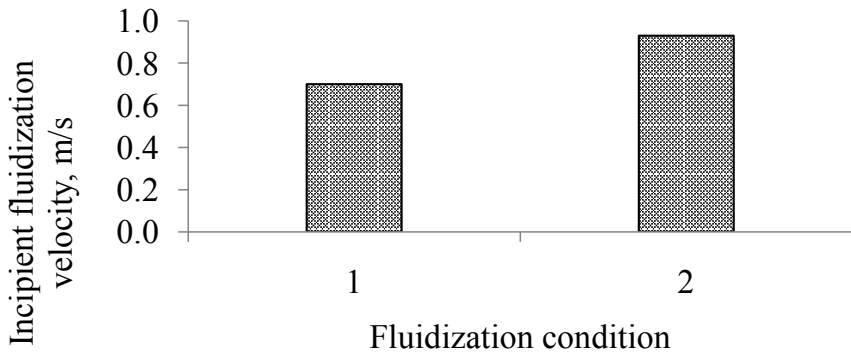

Figure 3: Effect of Vibrations on incipient velocity: 1) is non vibrated fluidized bed, 2) is vibrofluidized bed. Product- Acid casein, Particle size $-3.075 \mathrm{~mm}$, Bed weight $-0.7 \mathrm{~kg}$, Bed area $-0.0552 \mathrm{~m}^{2}$.

mathematical models were developed for predicting the drying process in vibrofluidized bed systems. Marella et al., [9] correlated various factors that impact the removal of moisture in Vibrofluidized beds. Dimensional analysis of the factors affecting the moisture removal process in a Vibrofluidized bed resulted in to an equation:

$$
\frac{M m}{M o}=\left(\frac{(E t / A b)^{3} m p m^{4} A v^{6} V b^{10 / 3}}{m p d\left(m o \cdot L^{6}\right) D p^{4}}\right)^{1 / 6}
$$

Where $\mathrm{Mm}$ and Mo are average and initial moisture content (\% dry basis), respectively, Et is total energy of the bed, J; $\mathrm{Ab}$ is area of the bed, $\mathrm{m}^{2} ; \mathrm{Ab}$ is vibratory acceleration, $\mathrm{m} / \mathrm{s}^{2}, \mathrm{mpm}$ is mean mass of the product, kg; mpd is mass of bone dry product, $\mathrm{kg}$; $\mathrm{Vb}$ is volume of the bed, $\mathrm{m}^{3}$; $\mathrm{Dp}$ is diameter of the particle, $\mathrm{m}$; mo is initial moisture content, $\mathrm{kg}$; and $\mathrm{L}$ is latent heat of evaporation, $\mathrm{J} / \mathrm{kg}$.

In drying of acid casein and agricultural grains (wheat and shelled corn) with particle size ranging from 1 to $5 \mathrm{~mm}$ size, the above model predicted initial and final drying time within $10 \%$ and $20 \%$ of the actual time, respectively.

Centrifugal force: Use of centrifugal force in fluidized bed drying is relatively new development and has been developed for high rate drying of sticky, high moisture piece form food stuffs [21]. In these dryers, food materials are placed on a rotating perforated drum, and subjected to high gas velocities [8]. Diced, sliced, shredded vegetables, carrots, apple and potato have been dried with the use of centrifugal fluidized bed dryers.

Immersed heaters: Variousconfigurations of immersed tube heat exchangers have been used in fluidized bed systems. The orientations range from horizontal, verticle to inclined. In addition to aiding the heat transfer characteristics, the presence of these internal structures retards the coalescence of bubbles and there by improve the bed structure [22]. When drying high moisture containing foods, it is essential to improve the moisture holding capacity of the air passing through the bed of the material. Internal immersed heaters provide the additional heat needed within the bed. The contact heat transfer coefficients obtained with the immersion heaters range from 500 to $800 \mathrm{~W} / \mathrm{m}^{2} \mathrm{~K}$, which are almost $100 \%$ more than the heat transfer coefficients obtained from fluidized and Vibrofluidized beds.

Two and Multi Stages: When the moisture content of the product is high, it is difficult to process the product in conventional systems. In that case, the product can be processed in two stages. In the first stage, one of the possible approaches is to process the product with the help of mechanical agitators. Then the preprocessed product is further processed in the second stage. The drying air from the second stage can be used in the first stage, either sigly or in combination with some fresh air. This type of arrangement reduces the heat consumption and space requirements [21].

In two stage spray drying, the product is processed in the spray drier at a relatively higher moisture level, followed by second drying in a vibrofluidizer. In this, the need of mechanical agitators is avoided by appropriate control with air to provide adequate cushioning against sticking. In multi stage spray drying, drying is accomplished in three stages, first in spray drying chamber second in an integrated fluidizer and third in an auxiliary vibrofluidizer. In this type of arrangement, around 20 and $30 \%$ savings in energy for two and multi stage, respectively, have been reported [23].

\section{Conclusions}

Drying is one of the most energy intensive operations in several process industries. The share of energy use in drying ranges from 10 - $25 \%$ of total energy used in the industrial processing. It is difficult to estimate drying energy use in food sector because of several factors that involve. Drying of dairy, food and agricultural material involve handling and processing of material with a wide range of moisture content. More over the variation in size and shape of the particles pose serious problem in efficient design and development of dryers. In order to make the dehydration systems more efficient, it is essential to take advantage of drying aids. This article reviewed some of the promising technologies that enhance the heat and mass transfer rates in drying of agrifood products. More and more research is needed in development of mathematical models for design of industrial drying systems.

\section{References}

1. Chung DS, Chang DI (1982) Principles of food dehydration. J Food Protection 45: $475-478$

2. Fortes M, Okos MR (1980) Drying theories: Their bases and limitations as applied to foods and grains. In: Advances in Drying (Mujumdar AS (Ed)) 1 : 119-154.

3. Kroll K, Mujumdar AS, Menon AS (1980) Drying since the millenniums. In drying '80 (Mujumdar AS Ed) 2: 485-494.

4. Prescott SC, Proctor BE (1937) Food Technology, McGraw Hill Book Co., NY.

5. Sokhansanj S, Jayas DS (1987) Drying of food stuffs. In: Handbook of Industrial Drying (Mujumdar AS Ed), Marcel Dekker, Inc. NY.

6. Holstrom P (1983) The energy evaluation in European dairy industry. The Australian J. Dairy Technol. 46-48.

7. Kroll K (1965) Trocknaeinteilevordenen, benennen, benummernschilde booklet, 6:14.

8. Senedeera W, Bhandari BR, Young G, Wijesinghe B (2000) Methods for effective fluidization of particulate food material. Drying technology 18: 15371557.

9. Marella C, Patel S, Shah US (1997) A mathematical model for vibrofluidized beds for drying casein. J Food Sci Technol 34: 153-154.

10. Marella C, Shah BP, Shah US (1997 b) Effect of transport variables on drying of casein in Vibrofluidized beds. Beverage and food world.

11. Marella C, Shah BP, Shah US, Siripurapu SCB (1999) Evaluation and testing of mathematical model on fluidized bed casein drying for corn and wheat. Journal of the Institution of engineers 79: 51-52.

12. Marella C, Patel S, Shah US (1996) Effect of Temperature of air on dehydration process in a Vibrofluidized system. Indian Journal of dairy science. 49: 502506 .

13. Sinz R, Lund DB (1974) Effect of vibration on drying rate of food particulates. Proc Biochem 27-34.

14. Mushtaev VI, Chevilenko BM, Korotkov BI (1972) The solubility of dried whole milk. Official Orgaon, Koninklijke, Nedrslandse, Zuivelhoand 66:190-192. 
Citation: Wimalawansa SJ (2013) Food Fortification Programs to Alleviate Micronutrient Deficiencies. J Food Process Technol 4: 257. doi:10.4172/21577110.1000257

15. Osinskii VP, Sazhin BS, Chuvpilo EA (1969) Results of tests on a dryer with a vibrated fluidized bed. Chem Petrol Eng 5: 866-869.

16. Sugiyama S, Arai N, Kume T, Shiga A (1975) Drying of Solid Particles in an Inclined Fluidized Bed. Kagaku kogaku Ronbunshu 1: 594-598.

17. Zaitsev ED, et al. (1977) Khim. Farm Zh., 11: 110-113.

18. Gupta R, Leung P, Mujumdar AS (1980) Drying of granular material in a vibro fluidized bed. In: Drying'80 (Mujumdar AS Ed) 2: 201-207.

19. Marella C (1991) Development of a mathematicl model for Vibrofluidized beds. M Sc thesis. Gujarat Agricultural University, Anand, India.
20. Ramesh MN, Sriniwasa Rao PN (1996) Drying studies of cooked rice in a Vibrofluidized bed dryer. Journal of Food Engineering. 27:389-396.

21. Hovmand S (1987) Fluidized bed drying. In: Handbook of Industrial Drying (Mujumdar AS Ed). Marcel Dekker, Inc. NY pp: 165-225.

22. Gupta R, Mujumdar AS (1980) Aerodynamics and thermal characteristics of vibrated fluid beds-a review. In drying'80 (Mujumdar AS Ed) Vol 1, Hemisphere, Washington. 141-150.

23. Pisecky J (1983) New generation of spray dryers for milk products. Dairy Industries International, 48: 21-24. 